\title{
Health impact assessment of traffic-related air pollution in Copenhagen Municipality
}

Brønnum-Hansen, Henrik; Bender, Anne Mette; Andersen, Zorana Jovanovic; Sørensen, Jan; Bønløkke, Jakob Hjort; Boshuizen, Hendriek; Becker, Thomas; Diderichsen, Finn; Loft, Steffen

Published in:

European Journal of Public Health

DOI:

10.1093/eurpub/cky213.204

Publication date:

2018

Document license:

CC BY

Citation for published version (APA):

Brønnum-Hansen, H., Bender, A. M., Andersen, Z. J., Sørensen, J., Bønløkke, J. H., Boshuizen, H., Becker, T., Diderichsen, F., \& Loft, S. (2018). Health impact assessment of traffic-related air pollution in Copenhagen Municipality. European Journal of Public Health, Volume 28(Issue suppl_4), 71-72.

https://doi.org/10.1093/eurpub/cky213.204 
Health impact assessment of traffic-related air pollution in Copenhagen Municipality

Henrik Brønnum-Hansen

H Brønnum-Hansen ${ }^{1}$, AM Bender ${ }^{1}$, ZJ Andersen ${ }^{1}$, I Sørensen ${ }^{2}$, J Bønløkke ${ }^{3}, H$ Boshuizen ${ }^{4}, T$ Becker ${ }^{5}, F$ Diderichsen ${ }^{1}, S$ Loft $^{\prime}$

${ }^{1}$ Department of Public Health, University of Copenhagen, Copenhagen, Denmark

${ }^{2}$ Healthcare Outcomes Research Centre, Royal College of Surgeons in Ireland, Dublin, Ireland

${ }^{3}$ Department of Public Health, Aarhus University, Aarhus, Denmark 
${ }^{4}$ Department Statistics, Informatics and Mathematical Modelling, National Institute for Public Health and the Environment, Bilthoven, Netherlands

${ }^{5}$ Department of Environmental Science, Aarhus University, Aarhus,

Denmark

Contact: henrik.bronnum-hansen@sund.ku.dk

Background:

High-resolution exposure to traffic-related air pollution can be assessed by modelling levels of nitrogen dioxide (NO2) which together with ultrafine particles mainly originate from dieselpowered vehicles in urban areas. The purpose of the study was to estimate the health benefits of reduced exposure to vehicle emissions assessed as NO2 among the citizens of Copenhagen Municipality, Denmark.

\section{Methods:}

We utilized residential NO2 concentrations modelled by use of chemistry transport models to calculate contributions from emission sources to air pollution. We used exposure-response functions linking NO2 concentration estimates with the risk of diabetes, cardiovascular diseases, and respiratory diseases derived from a large Danish study. The DYNAMO-HIA model was applied to the population of Copenhagen by using residential NO2 concentrations combined with demographic data and data from nationwide registers on incidence and prevalence of diseases associated with air pollution. Different scenarios were modelled to estimate the impact of NO2 exposure on related diseases and the potential health benefits of lowering the NO2 level in Copenhagen.

\section{Results:}

If $\mathrm{NO} 2$ exposure was restricted to the rural level life expectancy in 2040 would increase by two years for men and almost a half year for women. The greatest gain in disease-free life expectancy for men would be lifetime without ischemic heart disease (2.2 years), chronic obstructive pulmonary disease (2.1 years), and asthma (2.3 years). Among women the greatest increase would be lifetime without diabetes (1.2 years) and without stroke (1.1 years).

\section{Conclusions:}

Reducing the NO2 exposure by controlling traffic-related air pollution reduces the occurrence of some of the most prevalent diseases and increases life expectancy which can be quantified by DYNAMO-HIA with a high resolution exposure modelling. This tool has demonstrated how traffic planners can assess health benefits from reduced levels of traffic-related air pollution

\section{Key messages:}

- Lowering NO2 exposure by reducing traffic-related air pollution would reduce occurrence of cardiovascular, respiratory and metabolic diseases, lung cancer, and increase disease-free life expectancy.

- The full potential of health gain by reducing NO2 exposure level to that of rural areas would increase life expectancy in Copenhagen by two years for men and almost a half year for women. 